\title{
Directing toxins to cancer cells
}

from Sjur Olsnes

A CENTRAL PROBLEM in cancer chemotherapy is the lack of selectivity of present anti-cancer drugs. One attempt to improve this selectivity has involved the linking of cytostatic drugs, like daunomycin, adriamycin and methotrexate, to antibodies against tumour-associated surface antigens ${ }^{1,2}$. The ability of such complexes to kill malignant cells selectively has, so far, been limited. Blythman and his colleagues (see this issue of Nature, p.145) are among those who have tried an alternative approach, whereby a toxin, instead of a drug, is linked to the antibody, and have now succeeded in producing a complex which is not only toxic but also highly selective.

The limited success of the drugantibody complexes may be partly due to the fact that the cytostatic drugs act stoichiometrically and a large number of molecules is required to kill a cell. Even if the antibodies have the required selectivity (and it is not yet clear to what extent the corresponding antigens are tumour specific), they are usually obtained in such low amounts that the number of complexes reaching the tumour cells and binding to them may be very small. Furthermore, if the cytostatic drugs are for some reason released from the antibody, their nonselectivity is restored.

Interest in the preparation of tumourspecific cytostatics has recently increased for two reasons. First, the hybridoma technique permits the production of large amounts of monoclonal antibodies to a variety of cell-surface antigens, including tumour-associated ones. Second, the extreme toxicity of certain bacterial and plant toxins - a single molecule may kill a cell - might compensate for the small amount of complexes accumulating in the tumour.

Diphtheria toxin, abrin, ricin and related toxins all consist of two polypeptides with different functions. A binding polypeptide (B), with specificity for receptors at the cell surface, is linked by a disulphide bond to an enzymatically active polypeptide (A), which enters the cytoplasm and inactivates components of the protein-synthesizing machinery. Clearly, if the B-polypeptide is replaced by an antibody to a tumourassociated antigen, the enzymatically active A-polypeptide might be selectively delivered to the malignant cells. It is also important that the A-polypeptide alone is not cytotoxic.

In the first attempts to link diphtheria toxin to antibodies ${ }^{3,4}$ only marginal selectivity was achieved, but later studies have been much more successful. Thorpe $t$ al. 5,6 linked diphtheria toxin to antilymphocyte globulin and to $F\left(a b^{\prime}\right)_{2}$

Sjur Olsnes is at the Norsk Hydro's Institute for Cancer Research, Montebello, Oslo. fragments derived from it. These complexes were highly toxic to cultured human lymphoblastoid cells which are rather insensitive to diphtheria toxin alone. A chimaera of diphtheria toxin fragment $\mathbf{A}$ and $\mathrm{Fab}$ fragments of IgG from antiserum against L 1210 cells also showed selective toxicity in cell culture? . An interesting toxic conjugate was formed of ricin A-chain and anti-idiotype antibodies against surface immunoglobulins on a B-cell lymphoma ${ }^{8}$. This procedure may have a more general application as idiotypic antigens on the surface of B-cell lymphomas are, in fact,specific for the particular tumour cells.

During the past year four groups have reported experiments linking toxin A-chains by a disulphide bond to monoclonal antibodies against cell-surface antigens. In one case the antibody was against a colorectal tumour-associated antigen $^{9}$, whereas in the others they were against normal surface antigens like IgM and IgD on B lymphocytes ${ }^{8}$ and the differentiation antigen Thy-1.2 on thymocytes ${ }^{10}$. In each case the chimaeric toxins were selectively toxic to cultured cells carrying the corresponding antigen.

The chimaera or 'immunotoxin' formed by Blythman et al., between ricin A-chain and a monoclonal IgM antibody against the Thy-1.2 antigen, was almost as toxic as native ricin to murine lymphoma cells (WEHI-7) carrying the Thy-1.2 antigen. In contrast, cells lacking the Thy-1.2 antigen tolerated 2,000-6,000 times more immunotoxin although they were fully sensitive to native ricin. The authors also demonstrate that treatment with immunotoxin significantly increased the survival time of mice challenged with WEHI-7 lymphoma cells. Although promising, the protection in vivo was less than expected from the cell culture data. There may be several reasons for this discrepancy. As pointed out by the authors, the two test systems used are entirely different - in vivo a few surviving cells may grow up to tumours and kill the animal, whereas in the cell culture assay a few surviving cells would hardly be recognized. Furthermore, in vivo the access of immunotoxins to the lymphoma cells may be reduced, for example due to the removal of the chimaeras by reticuloendothelial cells ${ }^{11}$. Clearly, pharmacokinetic studies will be required to design the optimal type of immunotoxin.

Binding moieties other than antibodies have also been exploited. Several groups have made cytotoxic chimaeras by linking toxin $A$-chains to concanavalin $A^{12,13}$ and other lectins ${ }^{14}$, to asialofetuin ${ }^{15}$ which is taken up selectively by receptors on hepatocytes, and to monophosphopentamannose $\mathrm{e}^{16}$ which is bound and internalized by receptors on fibroblasts.
Particularly interesting are chimaeras between toxin $\mathrm{A}$-chains and hormones like insulin ${ }^{17}$, the $\beta$ subunit of human chorionic gonadotropin $^{18}$ and epidermal growth factor $^{19}$. The fact that the hormones are able to direct the toxin A-chain to the cytoplasm and kill the cell may be used to select mutant cells lacking hormone receptors and mutants with defects in the route of internalization. Such mutants may elucidate the functional significance of receptor-mediated endocytosis of polypeptide hormones Not all hormone receptors may be able to internalize chimaeric toxins, as shown by Chang et $a l .^{20}$ who could not demonstrate any toxic effect of a conjugate of diphtheria toxin fragment $\mathrm{A}$ and human placental lactogen.

Future work may take advantage of the fact that many plants accumulate considerable amounts of A-chain-like proteins which, as such, are not toxic to cells as they lack a B-chain. One of these proteins, gelonin, which is particularly abundant, became cytotoxic after being linked by a disulphide bond to concanavalin $\mathrm{A}^{21}$.

A limitation to the therapeutic use of chimaeric toxins is that, as foreign proteins, they elicit the production of neutralizing antibodies. This can, however, be considerably retarded if the toxins are given together with immunosuppressive cytostatic drugs ${ }^{22}$. Furthermore, the present availability of a variety of immunologically unrelated A-chains may allow a switch to another chimaera as soon as an immune response is detectable.

. I.evy, R., Hurwitz, E., Maron, R., Arnon, R. \& Sela, M Cancer Res. 35, 1182 (1975).

2. Ghose, T. \& Blair, A.H. J. natn. Cancer Inst. 61, 657 (1978)

Moolten, F.L. \& Cooperband, S.R. Science 169, 68 (1970)

4. Philpolt, G.W., Bower, R.J.\& Parker, C.W. Surgery 73 928 (1973).

Thorpe P E et al Nature 271, 752 (1978).

6. Ross, W.C.J. et al. Eur. J. Biochem. 104, 381 (1980).

7. Masuho, Y., Hara, T. \& Noguchi, T. Biochem. biophys Res. Commun. 90, 320 (1979).

8. Krolick, K.A., Villemez, C., Isakson, P., Uhr, J.W. \& Vitetta, E.S. Proc. natn. Acad. Sci. U.S.A. 77, 5419 (1980) Gilliland, D.G. et al. Proc. natn. Acad. Sci. U.S.A. 77 4539 (1980).

10. Youle, R J \& Neville, D.M Jr Proc natn Acad Sci. U.S.A. $77,5483(1980)$

11. Refsnes, K. \& Munthe-Kaas, A.C. J. exp. Med. 143, 1464 (1976).

12. Gilliiand, D.G., Collicr, R.J., Moehring, J.M. \& Moehring, T.J. Proc. natn. Acad. Sci. U.S.A. 75, 5319 (1978)

Yamaguchi, T. et al. J. natn. Cancer Inst. 62, 1387 (1979).

14. Uchida, T., Medada, E. \& Okada, Y. J. hiol. Chem. 255. $6687(1980)$.

5. Cawley, D.B. Simpson, V.L. \& Herschman, H.R. Fedn Proc. 39, 1798, Abstr. 1015 (1980).

16. Youle, R.J., Murray, G.J.\& Neville, D.M. Jt Proc, natn. Acad. Sci. U.S.A. 76,5559 (1979)

7. Miskimins, K.W. \& Schimizu, N. Biochem. hiophys. Res. Commun. 91, 143 (1979).

18. Oeltmann, T.N. \& Heath, E.C. J. biol. Chem. 254, 1028 (1979).

19. Cawley, D. B., Herveluman, H R Gilliland, D.C \& Collier, R.J Cell 22, 563 (1980).

20. Chang, T.-M., Dazord, A. \& Neville, D.M. Ir J. biol. Chang, T.-M., Dazord,

21. Stirpe, F., Olsnes, S. \& Pihl, A. J. biol. Chem. 255, 6947 (1980)

22. Moolien, F.L., Capparell, N.J. \& Zajdel, S.H. J. nain. Cancer Inst. 55, 709 (1975) 